\title{
A crítica da crítica do pensamento político
}

\author{
Critique of the critique of political thought
}

\author{
Robert Wegner \\ Pesquisador da Casa de O swaldo Cruz/Fiocruz \\ rwegner@pobox.com
}

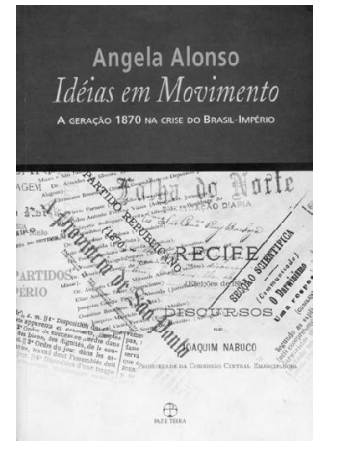

Angela Alonso

Idéias em movimento: a geração de 1870 na crise do Brasil-Império São Paulo, Paz e Terra, 2002, 392p.
M uitas são as disputas que atravessam o pensamento político no Brasil e as suas interpretações: centralizadores ou federalistas, primazia do Estado ou da sociedade, estamento burocrático ou patrimonialismo, cópia ou originalidade, idéias no lugar ou fora dele. Q uase surpreendente é constatar o quanto a geração de 1870 tem sido eleita como terreno para os contendores realizarem sua disputa. É desse período, já muito visitado portanto, que Angela Alonso se ocupa neste livro. Missão difícil, pois envolve uma grossa camada de interpretações e forte despertar de paixões. A autora enfrenta de forma direta tais interpretações, e o próprio título que atribui a sua obra nos remete ao debate incitado na década de 1970 por Roberto Schwarz, ainda que a autora não pretenda perguntar se as idéias estão fora do lugar, mas perceber as 'idéias em movimento'.

Na sua missão, realizada com uma redação escorreita e, embora agradável, por vezes seca, Angela Alonso recorre a armas que podem ser aludidas ao marcante texto de Quentin Skinner, de 1969, uma vez que Charles Tilly, um dos autores cruciais para a arquitetura do livro, trabalha de forma muito próxima às questões elaboradas pelo autor britânico (Skinner, 1988). Mas se o trabalho de idéias em contexto não é tão novo entre nós, pode-se dizer que poucas vezes teve tanto rendimento.

Angela Alonso não faz longas digressões teóricas sobre 'significado' e 'contexto', e ao invés de perguntar genericamente sobre a validade de se pensar as idéias em uso, opta por argumentar em prol de sua aplicabilidade no contexto específico do Segundo Reinado, mostrando que, no caso, não se pode falar em um campo intelectual autônomo. Portanto não cabe interpretar, por exemplo, o emprego de epítetos como positivismo ou darwinismo como uma tentativa, por parte dos atores, de fundar uma escola de pensamento. Aqui já se vislumbra uma das frentes de polêmica sustentadas pela autora com autores como Antonio Paim e João Cruz Costa, que, ao buscarem mapear a formação de doutrinas no Brasil, acabam por se perguntar acerca da coerência das idéias assumidas por autores brasileiros com os sistemas elaborados no pensamento europeu, como que se perguntando se os nacionais haviam entendido corretamente os estrangeiros. Para Alonso esta é uma questão levantada pela própria forma de se elaborar o problema, e uma vez considerado que aqueles qualificativos eram mobilizados em polêmicas políticas - e aqui é necessário salientar que mesmo um livro de filosofia pode, ou deve, ser compreendido no contexto político e no contexto intertextual em que é escrito ou proferido - , deve-se ter em mente que os autores não tinham exa- 
tamente por objetivo construir um corpus filosófico coerente; suas idéias só podem ser compreendidas se observadas na luta política e suas autodenominações, se analisadas como intuito polêmico e de formação de grupo para aquela luta.

Contudo, o que dá sentido a esse "bando de idéias novas" - na expressão de Sílvio Romero - a ponto de, mesmo formando doutrinas em trincheiras diversas e muitas vezes sem coerência interna, ainda ser possível falar em 'geração de 1870'? Não é no lugar social dos autores que Angela Alonso encontrará tal unidade - e acrescente-se que são exatamente aqueles autores que procuram explicar as correntes de pensamento a partir das suas origens nos estratos sociais o outro objeto de crítica da autora. Podemos dizer que, se antes a polêmica era com os textualistas, Alonso volta-se agora aos externalistas. No entanto, neste caso é uma crítica de outra natureza, pois, em termos gerais, o livro fica mais próximo desta linha de interpretação que leva em conta o contexto. A avaliação que a autora faz da obra de Cruz Costa pode esclarecer este ponto.

Para Cruz Costa, a tarefa da história das idéias no Brasil seria, nas palavras da autora, o estudo da ''deformação' das teorias estrangeiras para servir no Brasil como 'instrumentos de ação', uma vez que nos afastamos das metafísicas e nos impelimos 'para a meditação das realidades concretas e vivas'" (p. 25). Afora o qualificativo 'deformação', o projeto de Cruz Costa não descreve de modo muito infiel a tarefa a que a própria autora se impõe. Entretanto, além de entender a transformação das idéias como intrínsecas ao seu movimento e sua aplicação, e não uma singularidade da história intelectual do país, a autora critica a consecução do projeto do filósofo, porque apesar de supor uma sociologia não a realiza. Nesse caminho, mesmo partindo de um enquadramento sociológico, a obra de Cruz Costa acabaria por ficar mais próxima de um textualismo.

Alonso se afasta definitivamente do textualismo, pois para ela "a apreensão do significado do movimento intelectual impõe ir além da reconstrução da lógica interna dos textos" para "inscrever sua produção doutrinária no processo sociopolítico em que surge" (p. 38). Muitos estudos já realizados podem ser considerados efetivamente contextualistas, aqueles que procuram descobrir a extração social e regional dos grupos que formam a geração de 1870. A autora considera-se mais próxima deles, salientando que "esta linha de análise traz ganhos explicativos justamente por documentar uma variedade de grupos se apropriando das 'novas doutrinas'" (p. 28). Desse modo, acedendo à síntese de Alfredo Bosi, que em Dialética da colonização analisa tais estudos em conjunto, adquire-se uma visão panorâmica: "'positivismo ortodoxo' na Corte; 'spencerianismo paulista'; positivismo 'modernizador e de bem-estar' no Rio Grande do Sul; e 'novo liberalismo' no Nordeste" (p. 38). Sem desviar os olhos desta diversidade, Angela Alonso pondera que para ir além da mera somatória dos estudos é necessário captar o que os grupos têm em comum, o que é possível divisar não na extração social mas na política, uma vez que a experiência compartilhada pelos diferentes grupos era a de "marginalização em relação à dominação saquarema" (p. 100). 
Para entender a marginalização política, a autora nos remete à "modernização incompleta" operada na década de 1870 com as medidas elaboradas pelo gabinete de Rio Branco, nem sempre aprovadas sem restrição no Legislativo (cf. p. 86) mas que significaram uma reconfiguração social e política que atingiu "todosos grupos sociais, provocando não apenas a emergência de 'novos' segmentos, mas a desestruturação e reorganização dos antigos" (p. 28, grifo no original). Assim começa a se delinear uma "comunidade de experiências" entre aqueles grupos tão díspares.

As reformas Rio Branco parecem ter sido uma tentativa de desatar o clinch em que se encontravam as elites representadas por liberais e conservadores - aqui recorro à expressão de Elias (2001, pp. 272-3) em A sociedade de corte, quando o autor aplica às relações sociais a imagem esportiva de dois boxeadores segurando-se mutuamente. Tentando superar crises estruturais advindas com a emergência de como diria Florestan Fernandes - uma ordem social competitiva na estrutura patrimonial do Império (cf. p. 78), as reformas trouxeram conseqüências imprevistas, pois ainda que não tenham conseguido desatar os dilemas do Segundo Reinado, bastaram para que a elite operasse as mudanças necessárias para criar um "micro-espaço público" (capítulo 4, esp. p. 276), além de aumentar as expectativas de oportunidades políticas para além dos muros da Corte. Neste quadro, a despeito de seu lugar social, todos os grupos da geração de 1870 compartilhavam a experiência de estarem fora do núcleo de poder costurado pela obra saquarema desde 1841 e que então se fraturava, o que os impulsionou a se "engajarem em ações coletivas" (p. 95).

Também o rompimento do equilíbrio entre liberais e conservadores obrigou a que aquilo que era tácito no regime fosse defendido de modo explícito. Uma vez atacadas, as instituições do regime tinham de ser publicamente justificadas pelos fiadores do status quo, gerando o que a autora, seguindo Fritz Ringer, denomina "clarificação" (cf. p. 52). Nesse processo os três pilares que sustentavam a ordem imperial vêm à tona: o 'indianismo romântico', que, sem relação com o índio real, vinculava a aristocracia a uma imaginária nobreza da terra, dandoIhe um caráter de autenticidade nacional (cf. pp. 56-8); o 'liberalismo imperial', relativo à "noção de desigualdade natural entre os homens e à convicção de que a 'tirania do número' seria a maior ameaça à liberdade" (p. 61); e o 'catolicismo hierárquico', entendido como cimento moral de uma sociedade estratificada (cf. pp. 64-5). Assim, além da expansão das oportunidades políticas, a conjuntura da virada dos anos 1860 para os 1870 deslindou para os contendores seus recursos políticos e simbólicos: as armas dos grupos sociais nãomarginais tornaram-se claras, bem como os alvos a serem atingidos pelos que formam a geração de 1870 .

Percorrendo então essa geração, a autora avalia que diferentes analistas se deixaram capturar pela armadilha de estudar os grupos a partir dos seus próprios termos - especialmente de suas próprias autodenominações, como 'darwinistas' ou 'comteanos' - , o que levou os textualistas a procurarem a coerência dos autores brasileiros com seus congêneres europeus, enquanto que os contextualistas teriam 
perdido de vista o que os grupos concorrentes tinham em comum. Evitando tal caminho, Alonso considera que nomes de escolas e argumentações baseadas em doutrinas são mais bem compreendidos se examinados não como mera declaração de princípios filosóficos, mas como recurso de diferenciação e demarcação de posições políticointelectuais. Porém, de qualquer modo, estas não seriam as melhores chaves para mapear os grupos.

Sem desprezar outros estudos, a autora procura estabelecer uma tipologia alternativa da geração de 1870 organizando-a em seis grupos: liberais republicanos, novos liberais, positivistas abolicionistas (da Corte e de Pernambuco), federalistas (científicos de São Paulo e positivistas do Rio Grande do Sul). A esta altura, pode-se indagar sobre a vantagem de mais uma terminologia: não seria mais uma voz a se juntar em uma polifonia de interpretações sobre o fim do Império? Ocorre que no ato mesmo de nomear está presente a concepção que norteia toda a tessitura da obra: a impossibilidade de dissociar o movimento intelectual do político. Em geral os grupos são caracterizados por uma variável intelectual e uma política, porém isto não pode ser compreendido como duas caracterizações independentes ou mesmo em uma relação de determinação. Por exemplo, se um grupo for caracterizado como positivista abolicionista, não quer dizer que defendeu 0 abolicionismo porque abraçou idéias positivistas, ou, ao contrário, no ímpeto de acabar com a escravidão tenha procurado justificativas no ideário positivista. 0 ponto central é que tanto idéias quanto posição política são construídas ao mesmo tempo no processo de combate ao status quo imperial.

Desse modo, Angela Alonso argumenta que, se a variável regional e mesmo a sociológica podem ser explicativas deste ou daquele grupo, não dão conta de nos fazer entender a geração de 1870 como um todo. Talvez o mais fundamental seja que o livro procura demonstrar que "a mobilização da geração 1870 não foi ... uma resultante direta nem da origem social nem de interesses materiais compartilhados" (pp. 99-100). Aliás, o ponto cego de muitos estudos contextualistas repousaria no fato de que, ao tratar as idéias como ideologia que refletem as origens sociais dos seus portadores, perdem de vista as práticas dos agentes, deixando por esclarecer as mediações entre situação e idéias. Nas palavras da autora, esses intérpretes "têm privilegiado o adjetivo 'intelectual', perdendo o substantivo 'movimento'" (p. 34). Diante disso, a alternativa seguida é pensar os grupos a partir de sua distância "social em relação à estrutura estamental da sociedade imperial e sua posição política em relação à estrutura de poder do regime" (p. 160 grifos do original). Tal abordagem ajuda a compreender a formação de cada grupo sem que essas variáveis determinem, como veremos, o grau de radicalidade das suas propostas, como se quanto mais próximo do centro de poder menor fosse sua sanha reformista.

Com esse recurso a autora organiza "três microcontextos de experiência social", a partir dos quais se formaram os seis grupos do movimento intelectual da geração de 1870. Começando então pelo menor dos círculos concêntricos, temos as "dissidências liberais", caracterizadas pela grande proximidade da sociedade de corte e, a 
despeito dela, por um crescente distanciamento da ordem saquarema. Sua marginalização, portanto, "é de ordem política estritamente" ( $p$. 104). Neste primeiro microcontexto haveria dois grupos, os liberais republicanos e os novos liberais. No primeiro caso, falamos de homens como Quintino Bocaiúva e Aristides Lobo, ambos da imprensa. Em geral os liberais republicanos exerciam atividades políticas e desenvolviam negócios urbanos que obedeciam à lógica estamental. Nas palavras da autora, "suas atividades não estavam orientadas para 0 mercado. Movimentavam-se num mundo de transações comerciais dependentes do beneplácito de chefes partidários e/ou da sociedade de corte" (p. 106). No entanto diagnosticavam uma decadência da monarquia e prescreviam uma reforma política que gerasse descentralização e mudanças no sistema de representação.

Já os novos liberais, como André Rebouças e Joaquim Nabuco, teriam elaborado um diagnóstico mais estrutural: os problemas brasileiros resultavam da colonização (cf. p. 194), e a grande doença era a escravidão. Mesmo realizando uma oposição de dentro do centro de poder, decorria dela um programa pouco moderado (cf. p. 118). Por outro lado, explica a autora, sua estratégia para alcançar a abolição, uma mudança estrutural, confirmaria sua proximidade com o mundo da corte:

A reforma modernizadora nuclear, a abolição, prejudicaria a todos os proprietários, por isso nem liberais nem conservadores a fariam. Daí 0 recurso ao Poder Moderador. 0 'poder pessoal' 3/4 tão criticado pela velha geração liberal $3 / 4$ deixava de se apresentar como raiz dos males, para se tornar o caminho da reforma. ... Aderindo à monarquia, ao invés de insistir na mudança política, optaram por concluir as reformas emancipacionistas dos conservadores (p. 119).

Alargando o círculo, temos as "associações positivistas nas faculdades imperiais". Se os núcleos da Corte, que contavam com nomes como Teixeira Mendes e Miguel Lemos, estavam geograficamente mais próximos do centro de poder do que os núcleos de Recife - a autora é cética quanto à possibilidade de se falar em uma 'Escola de Recife' e mitiga a influência de Tobias Barreto (cf. pp. 133-5) 3/4 e de São Paulo, agora, em todo o caso, trata-se de grupos mais distantes socialmente da sociedade estamental e politicamente da ordem saquarema. De certo modo tais grupos foram fruto das reformas Rio Branco, que, ao ampliar o número de estudantes "sem a contraparte da dinamização do mercado de trabalho, reforçaram a concentração da população educada do Império e geraram o oposto do esperado: um grupo de demandantes" (p. 133).

A idéia de 'civilização' desses núcleos positivistas é a fonte de contestação de todos os pilares do Império: monarquia, escravidão, catolicismo e romantismo. Para a autora,

o repertório da política científica, e sobretudo o positivismo, operou esta transmutação da frustração individual com as carreiras na convicção política de que o regime monárquico, contaminado de filhotismo, não tinha futuro. Forneceu os instrumentos pelos quais a insatisfação com o ensino, com a 
distribuição de cargos, com a orientação 'literária' da elite, foi sendo identificada com causas mais profundas do 'estágio da civilização brasileira'. ... Transformou a dissonância de status em rebeldia política (p. 146).

O terceiro "microcontexto de experiência social" é o círculo mais distante social e politicamente do centro. São os "grupos regionais politicamente marginalizados". O coração do diagnóstico dos federalistas científicos estaria na dissociação entre Estado e nação, a qual era, segundo pregava a tradição imperial, resultado da centralização monárquica. Esta se tornava para eles, exatamente ao contrário, a responsável pelo sufocamento da identidade nacional e o empecilho para a marcha da civilização. Federalistas paulistas e gaúchos não apenas eram os grupos com maior grau de marginalização política, como seu projeto não contemplava integrar o núcleo da Corte; antes, "queriam mais autonomia para seus negócios" (p. 146).

Conforme Angela Alonso, o grupo federalista paulista, que congrega, por exemplo, Alberto Sales e Pereira Barreto, se assemelha aos positivistas abolicionistas por ter sido também "duplamente marginalizado", tanto distante da sociedade de corte como alijado do centro político. "A diferença importante - completa - é que tinham recursos econômicos próprios, meio que faltava aos demais grupos, o que lhes dava absoluta independência, tanto dos partidos quanto da corte de Pedro II" (p. 154). De seu lado, o também duplamente marginalizado federalismo positivista gaúcho, representado por Pinheiro Machado, Joaquim Francisco de Assis Brasil e Júlio de Castilhos, fazia seu diagnóstico da crise apontando a incapacidade de o sistema político processar as demandas dos que, como eles, estavam de fora das instituições políticas centrais. Como solução pregavam a República federativa. Explica a autora: “o repertório da política científica e, em particular, o positivismo, ajudou a formular o problema como anomia a ser superada por uma nova forma 'evolutiva'" (p. 258).

Para a estratégia explicativa de Alonso o fundamental não é dissecar a matriz teórica dos federalistas gaúchos, como seria esperado de um estudo internalista, para o qual quanto mais se falasse do positivismo mais se estaria a compreender o grupo. $\mathrm{Na}$ realidade, $\mathrm{o}$ que a autora procura ressaltar - e isso vale igualmente para os paulistas - é que "a crítica ao status quo imperial ... nascia da conjugação entre uma situação de marginalização política e contato com a política científica" (p. 158).

Isto nos traz novamente para o argumento central do livro, pois, como foi dito no início. Angela Alonso não toma como ponto de partida 'correntes filosóficas' para, a partir delas, compreender a geração de 1870. Ao contrário, é a partir do contexto social e intelectual e da luta política aí operada que entende seus atores. Desse modo, as idéias são consideradas 'ferramentas intelectuais' para os embates. Levando adiante a imagem, podemos dizer que, mais do que descrever tais ferramentas, a autora está preocupada em mostrar como elas eram manuseadas e quais engrenagens ou parafusos pretendia-se desmontar ou apertar. Assim o leitor visualiza as ferramentas em ação, e não guardadas em uma caixa. E se esta existe, é menos apresentada como, 
por exemplo, liberalismo ou positivismo, do que como 'política científica', entendida como "a simplificação e conversão das principais descobertas da sociologia nascente em argumentos e princípios de orientação política" (p. 238).

Inspirada no livro The transformation of liberalism in late Nin eteenthcentury Mexico, de Charles Hale, Angela Alonso expõe, com o conceito de 'política científica', o sumo, por assim dizer, das doutrinas que se tornaram correntes na segunda metade do século XIX, amparadas em duas idéias-chaves. Em primeiro lugar, uma 'teoria evolucionária da história': "da perspectiva científica, materialista, comum às teorias sociais da segunda metade do século XIX, o movimento intelectual reteve 0 diagnóstico sociológico de um movimento de mudança em escala mundial" (pp. 238-9). A história estaria caminhando "no sentido de desenvolvimento econômico e complexificação social; secularização, com a ciência substituindo a religião como orientação normativa da conduta; expansão da participação política e racionalização do Estado" (p. 239). E exatamente por se pensar uma correlação entre as esferas econômica, social, cultural e política tem-se, em segundo lugar, uma 'teoria da mudança política', a qual em certo sentido é uma teoria do gerenciamento daquele télos - daí a necessidade de uma intelligentsia (cf. p. 260). Isto traz uma modificação da concepção da própria política, pois, segundo a autora, "em oposição à preponderância das personalidades excepcionais na direção do Estado, glorificada no início do século (Rosanvallon, 1985), 'a política científica' recomendava a aplicação do saber sociológico na condução do governo, através de uma planificação racional das tarefas político-administrativas (Hale, 1989)" (p. 239).

Essas duas teorias que caracterizam a política científica demonstram que mesmo quando os integrantes da geração de 1870 dedicam-se a análise abstratas, estão a tecer críticas "às instituições, práticas e valores do status quo saquarema" (p. 244; grifo da autora). Portanto, mesmo livros como Positivismo e teologia (1880) de Pereira Barreto ou A evolução da matéria (1885) de Felisberto Freire, se analisados em seu contexto político e em comparação com textos da geração anterior, representam exatamente o oposto do bovarismo que os intérpretes costumam atribuir aos seus autores.

Não é exagero afirmar que o livro de Angela Alonso é um libelo contra esse tipo de interpretação, segundo a autora cristalizada em Do Império a República e na tese "do 'alheamento' em relação à realidade nacional" (p. 244), de Sérgio Buarque de Holanda. Isto não quer dizer que Alonso realize uma leitura benevolente dos autores da geração. O contrário acontece notoriamente quando disseca o 'elitismo' desta (cf. pp. 259-62): ao mostrar que para todos os grupos o motor da mudança política estava nas idéias, concorda em atribuir-lhes o epíteto 'idealismo utópico', cunhado por Oliveira Vianna (p. 261).

Alonso é bastante convincente ao combater a tese corrente do alheamento da realidade por parte da geração de 1870, mas a lembrança de Oliveira Vianna nos faz perguntar se não seria necessário distinguir dois planos traçados pelos críticos. Em resumo, é verdade que a autora nos convence de que "o fato de que alguns membros da 
geração 1870 formulem as questões do dia como parte de uma classe geral de problemas universais não anula o fato primeiro de estarem pensando sobre sua conjuntura" ( $p$. 38). Porém isto nos faz ver, ao mesmo tempo, que se trata de uma intervenção política concreta, operada com base em princípios abstratos. Neste sentido, é preciso acrescentar que uma faceta das críticas dirigidas à geração de 1870 não reforça tanto o seu alheamento frente à realidade, mas o fato de sua intervenção na política se dar a partir de pouca consideração ao que já existia.

É interessante notar que, quando Oliveira Vianna (1955, p. 414) discorre sobre o 'marginalismo' das elites - vivendo com o 'subconsciente coletivo' do país e, ao mesmo tempo, com 'diretrizes do pensamento' e 'critérios de julgamento político' europeus ou norteamericanos - , considera como caso exemplar Rui Barbosa, um dos 'novos liberais'. Sua respeitosa mas dura crítica a Rui Barbosa concentrase na militância deste durante a monarquia, sobretudo no fato de legislar tendo como referência um modelo de cidadão "que haviam imaginado os teoristas do Enciclopedismo e da Soberania do Povo" (idem, ibidem, p. 417), sem considerar as "representações coletivas ... que impropriavam o Brasil ... para a realização dos preceitos da Constituição de 91 - dos 'sonhos' do manifesto de 70, do regime federativo norte-americano, da autonomia municipal, das liberdades políticas e das liberdades civis e privadas ao modo inglês, que ele, Rui, idealizava" (idem, ibidem, p. 449).

Quanto a Sérgio Buarque de Holanda, é verdade que em Raízes do Brasil apresenta de forma quase anedótica nosso Benjamim Constant - mestre de positivistas da geração de 1870 como Teixeira Mendes e Miguel Lemos (pp. 129-30) - , às vésperas da instauração da República, orgulhar-se por nem sequer ler os jornais e ter votado apenas no último ano da monarquia, como a demonstrar sua aversão às coisas da política (Holanda, 1992, p. 118). No entanto, por outro lado, o autor destaca muito mais o fato de os positivistas acreditarem que "o mundo acabaria irrevogavelmente por aceitar [as novas idéias], só porque eram racionais" e viviam narcotizados "pela certeza de que o futuro os julgaria, e aos seus contemporâneos, segundo a conduta que adotassem ... em relação a [seus] princípios" (idem, ibidem, pp. 117-8, grifo do original).

Recorrendo à tese de Koselleck (1999), em Crítica e crise, é como se a geração de 1870 tivesse a marca iluminista de fazer política: se de fato não se ausenta da arena, realiza críticas 'morais' aos seus inimigos 'políticos'. Seus inimigos eram condenados pelo tribunal da razão e Ihes era anunciado que seriam vistos como superados pelos olhos do futuro. ${ }^{1}$ O ra, ao mesmo tempo que o livro de Angela Alonso demonstra que a geração de 1870 não tem nada de alheia ao real, evidencia igualmente que o engajamento político desta é marcado pelo apelo a princípios morais - daí positivistas abolicionistas e novos liberais, por exemplo, alertarem o imperador de que pagaria contas à posteridade

\footnotetext{
${ }^{1}$ Conferir também Hans Robert Jauss (1996), esp. pp. 60-5.
} 
(cf p. 305). A concepção moral da política é revelada ainda pelo próprio conceito de política científica, com sua cocepção teleológica da história e sua correspondente teoria da mudança política. Nesse sentido, se é correto afirmar que tais idéias estão em movimento, seus críticos, em boa parte, não estão a perguntar sobre seu lugar na realidade brasileira, mas a criticar sua origem em lugar algum.

Vale acrescentar, para concluir, que o livro é mesmo um convite à discussão, pois é ele próprio construído ao melhor estilo de um debate. A todo momento Angela Alonso procura deixar claro seus pontos de confluência e discórdia com outras leituras. Autores coetâneos da geração de 1870, contemporâneos da autora e intérpretes clássicos todas as peças estão no tabuleiro. Se isto já é uma virtude da obra, ainda pode servir como exemplo sua capacidade de tirar rendimento dos modernos debates realizados no interior de uma disciplina como história das idéias, para lançar um olhar denso sobre um período específico da história nacional. Por todos esses aspectos o livro tornase leitura obrigatória para os estudiosos da história intelectual ou social de qualquer época, pois sua marca maior é mostrar como é difícil fazer uma boa história das idéias sem história social e como esta se enriquece quando vem à luz o que vai pela cabeça de seus atores.

\section{REFERÊNCIAS BIBLIOGRÁFICAS}

Elias, Norbert 2001

Holanda, Sérgio

Buarque de 1992

Jauss, Hans Robert 1996

Koselleck, Reinhart 1999

Skinner, Quentin 1988

Vianna, Oliveira 1955
A sociedade de corte: investigação sobre a sociologia da realeza e da aristocracia de corte. Trad. Pedro Süssekind. Rio de Janeiro, Jorge Zahar.

Raízes do Brasil. 24를 ed.

Rio de Janeiro, José Olympio.

'Tradição literária e consciência atual da modernidade'.

Trad. Heidrun Krieger Olinto. Em H.K. Olinto (org.). Histórias de literatura: as novas teorias alemãs. São Paulo, Ática.

Crítica e crise: uma contribuição à patogênese do mundo burguês.

Trad. Luciana Villas-Boas Castelo-Branco. Rio de Janeiro, EdUerj/Contraponto.

'Meaning and understanding in the history of ideas'. Em J. Tully (ed.).

Meaning \& context: Quentin Skinner and his critics. Princeton, Princeton University Press, pp. 29-67.

Instituições políticas brasileiras, vol. II. 2ª ed.

Rio de Janeiro, José Olympio.

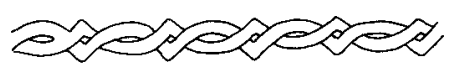

